\title{
New Onset Paroxysmal Atrial Fibrillation After Electroconvulsive Therapy
}

\author{
Michael R. Hower ${ }^{1}$, Chong Yang ${ }^{2}$ \\ 1. Psychiatry, Touro University of California - College of Osteopathic Medicine, Vallejo, USA 2. Psychiatry, California \\ Department of State Hospitals - Napa, Napa, USA
}

Corresponding author: Michael R. Hower, michael.hower@tu.edu

\begin{abstract}
Electroconvulsive therapy (ECT) is a safe treatment for various psychiatric disorders. During an ECT treatment, an electrical stimulus produces a transient sympathetic response leading to changes in the cardiac rate and rhythm. Rarely, ECT treatment may precipitate atrial fibrillation (AF). In this case report, we present a 70-year-old man with schizoaffective disorder who developed paroxysmal AF after his $38^{\text {th }}$ ECT treatment. We review his risk factors for $\mathrm{AF}$ and propose a possible mechanism of its development. We also discuss potential treatment options to safely resume ECT treatments.
\end{abstract}

Categories: Psychiatry

Keywords: ect, electroconvulsive therapy, atrial fibrillation

\section{Introduction}

Atrial Fibrillation (AF) is a cardiac arrhythmia defined by abnormalities in the structure or conduction of the heart that promote abnormal atrial impulse formation and/or propagation [1]. It is detected by the absence of $P$ waves and the presence of an irregular rate and rhythm on an electrocardiogram (EKG) [2]. The diagnosis is also classified by the duration of episodes. For example, the episode is "paroxysmal" when it begins suddenly and terminates within seven days [1].

The clinical presentation of AF may vary. A literature review indicates that up to $30 \%$ of patients with AF are asymptomatic. Otherwise, patients may present with a variety of symptoms, including palpitations, chest pain, dyspnea, fatigue, and more rarely, dizziness and syncope [3]. Regardless of the signs and symptoms, a cardiological assessment is necessary as AF is a clinically significant independent risk factor for stroke [4]. Therefore, patients should be evaluated and treated with their risk factors taken into consideration. Risk factors predisposing individuals to $\mathrm{AF}$ include increasing age, hypertension, obesity, diabetes mellitus, previous cardiovascular event, family history, European ancestry, alcohol use, and smoking [1]. The risk of $\mathrm{AF}$ is also higher in men than in women [5]. Finally, there are reports of new onset AF using antipsychotic medications, such as olanzapine and clozapine, likely due to their effect as an antagonist on muscarinic receptors in the heart [6-8].

Review began 11/09/2020 Review ended 11/18/2020 Published 11/26/2020

\section{๑) Copyright 2020}

Hower et al. This is an open access article distributed under the terms of the Creative Commons Attribution License CC-BY 4.0., which permits unrestricted use, distribution, and reproduction in any medium, provided the original author and source are credited.
The American Psychiatric Association supports the application of electroconvulsive therapy (ECT) as a treatment modality for major depression, mania, and schizophrenia. It is a safe medical procedure, and there are no absolute medical contraindications to ECT [9]. However, careful consideration is necessary for patients with cardiovascular disorders receiving ECT. The electrical stimulus produces a sympathetic response, including sinus tachycardia and transient EKG changes [10, 11]. This sympathetic response leads to increased oxygen consumption, blood pressure, and heart rate, which may cause additional stress on the heart [12]. Although ECT-induced AF is rare, this catecholamine surge may cause stretching of atrial fibers predisposing an individual to AF during treatment [13, 14]. In the following case report, we present a patient who developed atrial fibrillation after treatment with ECT.

\section{Case Presentation}

Our patient is a 70-year-old man hospitalized in a state hospital with a diagnosis of schizoaffective disorder, bipolar type. His psychotic symptoms include auditory hallucinations, disorganized speech, disorganized behavior, and paranoid delusions. His mood symptoms include mood swings, irritability, grandiosity, pressured speech, a flight of ideas, and impulsivity. He did not respond to multiple psychotropic medication trials during his hospitalization. Furthermore, he was a poor candidate for clozapine due to his constant refusals to obtain the necessary lab work. Therefore, he was referred for ECT treatment while remaining adherent to olanzapine 50 milligrams (mg)/day and lurasidone $160 \mathrm{mg} /$ day.

The patient was treated on the Thymatron ${ }^{\circledR}$ System IV (Somatics, LLC, USA) with a pulse width of 0.5 milliseconds. Other treatment parameters include bilateral stimulus electrode placement, 1 milligram/kilogram ( $\mathrm{mg} / \mathrm{kg}$ ) of methohexital as the anesthetic, and $1 \mathrm{mg} / \mathrm{kg}$ of succinylcholine as the muscle relaxant. Over the course of four months, he received 38 ECT treatments with partial relief of his psychotic 


\section{Cureus}

and mood symptoms.

After his $38^{\text {th }}$ ECT treatment, the patient developed atrial fibrillation during the recovery phase. His heart rate reached $140 \mathrm{bpm}$, and an EKG confirmed the presence of atrial fibrillation (Figure 1). He did not report palpitations, fatigue, weakness, or dizziness. However, he was transferred to the emergency department for an additional medical workup. The patient remained asymptomatic upon transfer to the emergency department. His laboratory workup was unremarkable: complete blood cell count, serum electrolytes, blood urea nitrogen, creatinine, thyroid-stimulating hormone, cardiac enzymes, prothrombin time, and international normalized ratio are within normal limits. His EKG in the emergency department revealed a normal sinus rhythm with a rate of $68 \mathrm{bpm}$. He was observed for two hours and discharged back to the state hospital with a diagnosis of cardiac arrhythmia.

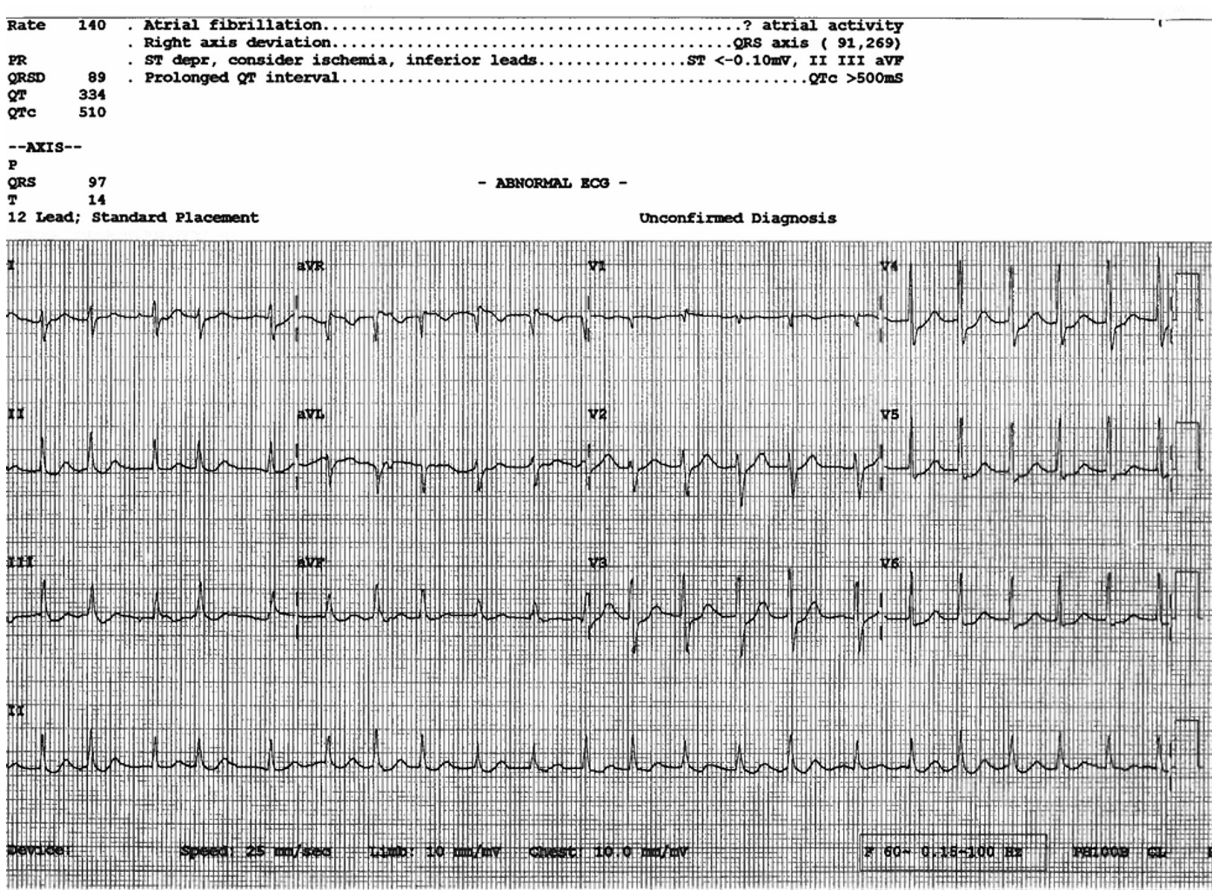

\section{FIGURE 1: EKG after the 38th ECT treatment}

The EKG is characterized by the absence of $\mathrm{P}$ waves and the presence of an irregular rate and rhythm.

\section{Discussion}

We presented a rare case in which a patient developed AF after treatment with ECT. We identified his age, gender, and antipsychotic medication (olanzapine) as his risk factors for AF. We propose that his risk factors and the sympathetic response with his ECT treatment precipitated his development of AF. Fortunately, the patient did not require immediate treatment due to his spontaneous conversion to normal sinus rhythm.

We reviewed the literature on the risks of continuing ECT for individuals with AF. Multiple case reports support the continuation of ECT treatment for individuals with AF [10, 13, 15]. Loeffler and Capobianco resumed ECT treatments in a healthy 46 -year-old man with AF after administering a calcium channel blocker (diltiazem) and spontaneous cardioversion [13]. Other antiarrhythmic drugs such as beta-blockers may serve as therapeutic and prophylactic solutions. Labetalol was found to be superior to esmolol for protection against the increase in heart rate and blood pressure [14]. However, esmolol has a lesser impact on decreasing the seizure duration in ECT $[14,16]$.

In addition to antiarrhythmic medications, anticoagulation and cardioversion are considerations for the treatment of AF. Suzuki et al. reported a case study in which a 77-year-old woman developed an embolic stroke one day after her last ECT treatment [17]. To mitigate this risk, Petrides and Fink recommend anticoagulation prior to the continuation of ECT treatment [15]. It is important to note that anticoagulation is necessary prior to cardioversion to reduce embolization risk [18].

\section{Conclusions}

In rare occurrences, patients develop atrial fibrillation during a course of ECT treatment. These patients should be assessed due to their increased risk of stroke. Furthermore, it is important to consider treatment 
of AF with antiarrhythmic medications, anticoagulation and/or cardioversion prior to the continuation of ECT treatment. These precautions minimize the risk of stroke so that they may safely resume ECT treatments.

\section{Additional Information \\ Disclosures}

Human subjects: Consent was obtained by all participants in this study. Conflicts of interest: In compliance with the ICMJE uniform disclosure form, all authors declare the following: Payment/services info: All authors have declared that no financial support was received from any organization for the submitted work. Financial relationships: All authors have declared that they have no financial relationships at present or within the previous three years with any organizations that might have an interest in the submitted work. Other relationships: All authors have declared that there are no other relationships or activities that could appear to have influenced the submitted work.

\section{References}

1. January CT, Wann LS, Alpert JS, et al.: 2014 AHA/ACC/HRS guideline for the management of patients with atrial fibrillation: executive summary: a report of the American College of Cardiology/American Heart Association Task Force on practice guidelines and the Heart Rhythm Society. Circulation. 2014, 2:20712104. 10.1161/CIR.0000000000000040

2. Henriksson M, Petrenas A, Marozas V, Sandberg F, Sörnmo L: Model-based assessment of f-wave signal quality in patients with atrial fibrillation. IEEE Trans Biomed Eng. 2018, 65:2600-2611. 10.1109/TBME.2018.2810508

3. Rienstra M, Lubitz SA, Mahida S, et al.: Symptoms and functional status of patients with atrial fibrillation: state of the art and future research opportunities. Circulation. 2012, 125:2933-2943. 10.1161/CIRCULATIONAHA.111.069450

4. Wolf PA, Abbott RD, Kannel WB: Atrial fibrillation as an independent risk factor for stroke: the Framingham Study. Stroke. 1991, 22:983-988. 10.1161/01.str.22.8.983

5. Heeringa J, van der Kuip DA, Hofman A, et al.: Prevalence, incidence and lifetime risk of atrial fibrillation: the Rotterdam study. Eur Heart J. 2006, 27:949-953. 10.1093/eurheartj/ehi825

6. Waters BM, Joshi KG, Flynn J: Olanzapine-associated new-onset atrial fibrillation. J Clin Psychopharmacol. 2008, 28:354-355. 10.1097/JCP.0b013e318173082c

7. Low RA Jr, Fuller MA, Popli A: Clozapine induced atrial fibrillation. J Clin Psychopharmacol. 1998, 18:170. 10.1097/00004714-199804000-00010

8. Chou RH, Lo LW, Liou YJ, et al.: Antipsychotic treatment is associated with risk of atrial fibrillation: A nationwide nested case-control study. Int J Cardiol. 2017, 227:134-140. 10.1016/j.ijcard.2016.11.185

9. American Psychiatric Association. Task Force on Electroconvulsive Therapy: The practice of ECT: recommendations for treatment, training and privileging. Convuls Ther. 1990, 6:85-120.

10. Harsch HH: Atrial fibrillation, cardioversion, and electroconvulsive therapy. Convuls Ther. 1991, 7:139-142.

11. Urzal F, Oliveira-Maia AJ, Barahona-Correa JB: Acute-onset atrial fibrillation following an electrically induced generalized convulsion in a patient treated with clozapine and electroconvulsive therapy. J ECT. 2019, 35:15-16. 10.1097/YCT.0000000000000558

12. Kelly KG, Zisselman M: Update on electroconvulsive therapy (ECT) in older adults . J Am Geriatr Soc. 2000, 48:560-566. 10.1111/j.1532-5415.2000.tb05005.x

13. Loeffler G, Capobianco M: Resuming electroconvulsive therapy (ECT) after emergence of asymptomatic atrial fibrillation during a course of right unilateral ECT. J ECT. 2012, 28:68-69. 10.1097/YCT.0b013e318238f032

14. Venditti RC, Shulman MS, Lutch SB: Atrial fibrillation after electroconvulsive therapy . Anaesthesia. 1992, 47:914-915. 10.1111/j.1365-2044.1992.tb03180.x

15. Petrides G, Fink M: Atrial fibrillation, anticoagulation, and electroconvulsive therapy . Convuls Ther. 1996, 12:91-98.

16. Partridge BL, Weinger MB: Comparison of pretreatments to prevent the cardiovascular response to ECT . Anesth Analg. 1990, 70:303.

17. Suzuki H, Takano T, Tominaga M, Suzuki K, Kagaya Y: Acute embolic stroke in a patient with atrial fibrillation after electroconvulsive therapy. J Cardiol Cases. 2010, 2:12-14. 10.1016/j.jccase.2010.01.004

18. Ottaway A: Atrial fibrillation, failed cardioversion, and electroconvulsive therapy . Anaesth Intensive Care. 2002, 30:215-218. 10.1177/0310057X0203000216 